\title{
Prevalence of unintended pregnancy and associated factors among pregnant women attending antenatal clinics
}

\author{
Eman H. Elshrqawy*, Amina M. Elnemr \\ Woman's Health and Midwifery Nursing, Faculty of Nursing, Mansoura University, Egypt
}

Received: October 4, 2020

DOI: $10.5430 /$ cns.v9n1p29
Accepted: December 13, 2020

Online Published: January 12, 2021

\begin{abstract}
Objective: Unintended pregnancy is an important worldwide public health problem and one of the important factors contributing to high level of maternal and child morbidity and mortality. The study was aimed to assess the prevalence and associated factors of unintended pregnancy among pregnant women attending antenatal clinics.

Methods: The study followed a descriptive cross-sectional design on 1,254 pregnant women who were chosen by convenient sample technique. The study was done at governmental hospitals in EL-Mansoura City, Egypt including: The antenatal clinics of Obstetric and Gynecological specialty Center at EL-Mansoura University Hospitals, Old General Hospital and Mansoura International Hospital. Two tools were utilized for data collection (The Urdu version of pregnancy intention scale (LMUP) and structured Interviewing Questionnaire.

Results: The prevalence of unintended pregnancy among studied women was (29.1\%), of which $229(18.3 \%)$ were mistimed and $136(10.8 \%)$ were unwanted. Age, higher family size, lower family income, gravidity, parity, increased number of children and birth spacing were significantly associated with unintended pregnancy.

Conclusions: The study concluded that the prevalence of unintended pregnancy was high in El-Mansoura city. It is recommended to develop educational programs and campaigns especially for rural areas to improve awareness regarding family planning and other co-factors associated with unintended pregnancy.
\end{abstract}

Key Words: Unintended pregnancy, Prevalence, Contraception, Associated factors

\section{INTRODUCTION}

Unintended Pregnancy (UP) is a major public health concern in the world as a result of its negative associations with the social, economic and health consequences for both mothers and children ${ }^{[1]}$ Unintended pregnancy is defined as pregnancy that either mistimed or unwanted at the time of conception regardless of women's contraceptive use. ${ }^{[2]}$

Unintended pregnancy is one of the most important repro- ductive health issues notable for women in reproductive age. According to World Health Organization, there are around 99.1 million (44\%) unintended pregnancies per year worldwide. Also, it is estimated that (39\% and $46 \%$ respectively) of all pregnancies in Africa and Eastern Africa were unintended. ${ }^{[3]}$ Furthermore, there was prevalence rate of (18.5\%) for unintended pregnancy in Egypt. ${ }^{[4]}$ Unintended pregnancy may occur due to different causes such as not utilizing contraceptive methods, contraceptive failure or contraceptive

\footnotetext{
*Correspondence: Eman H. Elshrqawy; Email: emynona911@yahoo.com; Address: Woman’s Health and Midwifery Nursing, Faculty of Nursing, Mansoura University, Egypt.
} 
discontinuation. Moreover, there are many factors associated with unintended pregnancy including extreme of ages less than 25 or over 40 years old, marriage at younger age, lower education and unemployed mothers, history of previous unintended pregnancy, high gravidity and parity. ${ }^{[5]}$ Unintended pregnancy may lead to severe and imposing effects on children, women, men and families. Women with UP are less likely to initiate early antenatal visits. ${ }^{[6]}$ Furthermore, unintended pregnancy may lead to negative consequences such as preeclampsia, anemia during pregnancy, substance abuse during pregnancy, preterm birth, cesarean section and low birth weight and also less likely to initiate or continue breast feeding after birth. ${ }^{[7]}$

\subsection{Significance}

Over population in Egypt is the biggest problem facing economy, it impedes the development of economic achievement. Egyptian strategy 2030 aims to reach 112 million by 2030 instead of 128 million by improving planned pregnancy and spacing between pregnancies. Accordingly, the Strategic National Population Plan 2015-2030 in Egypt has called for accelerated efforts to reduce the total fertility rate (TFR) to 2.4 births per woman by the year $2030 .^{[8]}$

Moreover, Centers for Disease Control and the Agency for Toxic Substances and Disease Registry Research and the Healthy People 2020 aims specifically to promote healthy outcomes of pregnancies by preventing unintended pregnancy, reducing unmet need for family planning from $(12.6 \%)$ in 2014 to $(10.6 \%)$ by 2020 , reducing the discontinuation rate (within 12 months of use) from (29\%) in 2014 to (24\%) by 2020 and increase the prevalence rate of all contraceptive methods used among married women from $(58.5 \%)$ in 2014 to $(62.8 \%)$ by $2020 .{ }^{[9]}$

\subsection{Aim of the study}

The present study aimed to assess the prevalence and associated factors of unintended pregnancy among pregnant women attending antenatal clinics.

\subsection{Research questions}

(1) What is the prevalence of unintended pregnancy among pregnant women attending antenatal clinics?

(2) What are the factors associated with unintended pregnancy among pregnant women attending antenatal clinics?

\section{SUBJECTS AND METHODS}

\subsection{Research design}

The study followed a descriptive cross-sectional design.

\subsection{Setting}

The study was conducted at governmental hospitals in ELMansoura City, Egypt including: The antenatal clinics of $\mathrm{Ob}$ stetric and Gynecological specialty Center at EL-Mansoura University Hospitals, Old General Hospital and Mansoura International Hospital. Mansoura city, Dakahlia governorate is located in the North Eastern region of Delta, Egypt.

\subsection{Sampling}

This study utilized a convenient sample of pregnant women who attended antenatal follow up at the antenatal clinic of governmental hospitals at EL-Mansoura over the period of six months from December 2019 to May 2020. Estimated sample size of 1254 of pregnant women.

\subsection{Sample size}

This aim of the study is to assess the prevalence and associated factors of unintended pregnancy among pregnant women attending antenatal clinics. Based on data from literature. ${ }^{[10]}$ Considering the power of the study is $80.0 \%$, with precision/absolute error of $5 \%$ and type 1 error of $5 \%$, then the sample size is calculated according to following Equation 1:

$$
\text { Samplesize }=\frac{\left[\left(Z_{1}-\frac{\alpha}{2}\right)^{2} \times P(1-P)\right]}{d^{2}}
$$

Whereas, $Z_{1}-\frac{\alpha}{2}=$ is the standard normal variate, at $5 \%$ type 1 error $(p<.0269)$ it is 1.96 .

$P=$ the expected proportion in population based on previous studies.

$d=$ absolute error or precision.

So, Sample size $=\left[(1.96)^{2} \times 0.38 \times(1-0.38)\right] / 0.05^{2}=$ $1,253.7$.

Based on the above formula, the sample size required for the study is 1,254 .

\subsection{Tool of data collection}

Two tools were utilized for data collection:

Tool (1): The Urdu version of pregnancy intention scale (LMUP), London measure of unplanned pregnancies

This tool was adopted from Barrett. ${ }^{[11]}$ This scale was used to assess the prevalence of unintended pregnancy. It includes 6 questions, each one scored as $0,1,2$, and the total score ranged from $(0 \pm 12)$. The higher score indicates increased pregnancy intention. The score of less than 3 indicates unintended pregnancy, more than 10 indicates intended pregnancy and scores of $4 \pm 9$ indicate ambivalence of pregnancy intention. 
Tool (2): A structured interviewing questionnaire

This tool was designed by the researcher after reviewing the related literatures. ${ }^{\left[{ }^{12}\right]}$ It was consisted of five parts to measure the following:

Part (1): Pregnant women's socio-demographic characteristic it includes: age, level of education, residence, marital status, age of marriage, occupation, family size, income... etc.

Part (2): Pregnant women's obstetrical history it covers the: gravidity, gestational age, birth interval, history of abortion, number of living children and desired number of children.

Part (3): Information about the current pregnancy and women's practices towards family planning method which includes questions about the intention of the current pregnancy, family planning methods used and reasons for not using FP methods. It also includes questions about antenatal follow up and reasons of not utilizing antenatal follow up services.

\section{Validity of the study tools:}

The validity of the study tools was checked by three experts in the field of obstetrics and gynecology nursing. Based on expertise's suggestions, minor modifications were done and the final form was used for data collection.

\subsection{Ethical considerations}

An official permission was taken from the Ethics Committee of the Faculty of Nursing, Mansoura University then an official letter from Faculty of Nursing, Mansoura University was directed to the head of the Antenatal clinic of Obstetric and Gynecological specialty center at Mansoura University Hospitals, Old General Hospital and Mansoura International Hospital in Mansoura city to obtain the official permission to conduct the study after explaining its aim. The purpose of the study was explained to the study subjects and a written consent to participate in the study was obtained. Participation in the study was voluntary and each participant had the right to withdraw from the study at any time. Anonymity, privacy, safety and confidentiality were absolutely assured throughout the whole study. The study subjects were informed that the result will be used as a component of the necessary research for Master study as well as for publication and education.

\subsection{Research process}

\subsubsection{Preparatory phase}

It included reviewing the local and international relevant literature and theoretical knowledge about the various aspect of the study using articles, books, journals to develop data collection tool which prepared by the researcher.

\subsubsection{A pilot study}

A pilot study was done on 126 women (10\% from the sample size) who attended at the antenatal clinics in the previously mentioned setting to evaluate the clarity and applicability of the tools that were used in the study before start of data collection as well as to determine the time needed for answer. The women engaged in the pilot study were excluded from the analyzed sample. This stage lasted one month (November 2019).

\subsubsection{Baseline assessment}

Data were collected for six months in the period from beginning of December 2019 to the end of May 2020 from the antenatal clinics in the above-mentioned setting after obtaining official permission to conduct the study. The researcher attended the previously mentioned setting three days weekly from 9 a.m. to 1 p.m. until the end of the six months. The researcher introduced herself to the health care provider and the women. Also, the aim of the study clarified and women's informed consent obtained for participation in the study after assuring the confidentiality of data.

The researcher interviewed each woman separately for about 15-20 minutes to gather data by using the first tool (London measure of unintended pregnancy) to determine the prevalence of unintended pregnancy among 1,254 convenient sample of pregnant women. After interviewing via face to face interview with the women using the first tool (see Appendix I), among 1,254 women there were 365 was determined as unintended pregnancy. Based on this result, only the 365 pregnant women with unintended pregnancy completed the interview with the researcher to complete the structured interviewing questionnaire as well as to assess the associated factors of unintended pregnancy.

The researcher completed the questionnaire which included questions about their socio-demographic characteristics and obstetrical data as well as their practices regarding family planning methods, their information about their previous pregnancy and current pregnancy. The questionnaire also included questions regarding their knowledge and practices about unintended pregnancy. Data were gathered by the researcher. Each woman was interviewed separately to give her chance to talk freely about her experience with unintended pregnancy.

\subsection{Statistical analysis}

All statistical analyses were conducted using SPSS for windows version 20.0 (SPSS, Chicago, IL). All continuous data were normally distributed and were expressed in mean \pm standard deviation $(S D)$. Categorical data were expressed in number and percentage. Chi-square test was used for com- 
parison of variables with categorical data. Cronbach's alpha test was preformed to test for the internal consistency of the tools used in the study. Statistical significance was set at $p<$ .05 .

\section{RESUlts}

Table 1 shows that $(34.2 \%)$ of the studied women aged more than 35 years with mean $\pm S D=31.8 \pm 7.0$. In addition, $(66.8 \%)$ of the studied women were married at the age of 20 years or less with mean $\pm S D=18.8 \pm 3.0$. The majorities of the studied women $(83 \%, 81.1 \%$ respectively) were lived in rural area and were housewives. Moreover, $(62.2 \%, 58.4 \%$ respectively) of the studied women were lived in family size four persons with inadequate income. Regarding education, nearly half of the studied women (47.9\%) attained secondary education only.

Table 1. Distribution of the socio-demographic characteristics of the studied women $(n=365)$

\begin{tabular}{|c|c|c|}
\hline Socio-demographic characteristics & $\mathbf{N}$ & $\%$ \\
\hline \multicolumn{3}{|l|}{ Age (years) } \\
\hline$\leq 25$ & 102 & 27.9 \\
\hline $26-30$ & 63 & 17.3 \\
\hline $31-35$ & 75 & 20.5 \\
\hline$>35$ & 125 & 34.2 \\
\hline Range & $18-43$ & \\
\hline Mean $\pm S D$ & $31.8 \pm 7.0$ & \\
\hline \multicolumn{3}{|l|}{ Age at marriage (years) } \\
\hline$\leq 15$ & 35 & 9.6 \\
\hline $16-20$ & 244 & 66.8 \\
\hline $21-25$ & 79 & 21.6 \\
\hline$>25$ & 7 & 1.9 \\
\hline Range & 13-33 & \\
\hline Mean $\pm S D$ & $18.8 \pm 3.0$ & \\
\hline \multicolumn{3}{|l|}{ Women's Educational level } \\
\hline Illiterate & 60 & 16.4 \\
\hline Read and write & 76 & 20.8 \\
\hline Middle education & 175 & 47.9 \\
\hline High education & 54 & 14.8 \\
\hline \multicolumn{3}{|l|}{ Residence } \\
\hline Rural & 303 & 83.0 \\
\hline Urban & 62 & 17.0 \\
\hline \multicolumn{3}{|l|}{ Women's occupation } \\
\hline Housewife & 296 & 81.1 \\
\hline Working & 63 & 17.3 \\
\hline Student & 6 & 1.6 \\
\hline \multicolumn{3}{|l|}{ Family size } \\
\hline $1-3$ & 98 & 26.8 \\
\hline $4-6$ & 227 & 62.2 \\
\hline$>6$ & 40 & 11.0 \\
\hline \multicolumn{3}{|l|}{ Family income } \\
\hline Not enough & 213 & 58.4 \\
\hline Enough & 135 & 37.0 \\
\hline Enough and saving & 17 & 4.7 \\
\hline
\end{tabular}

Table 2. Frequency distribution of the obstetric history of the studied women

\begin{tabular}{|c|c|c|}
\hline Obstetric history & $\mathbf{N}$ & $\%$ \\
\hline \multicolumn{3}{|l|}{ Gravidity } \\
\hline 1 & 66 & 18.1 \\
\hline 2 & 88 & 24.1 \\
\hline 3 & 95 & 26.0 \\
\hline$>4$ & 116 & 31.8 \\
\hline \multicolumn{3}{|l|}{ Parity } \\
\hline $1-2$ & 161 & 44.1 \\
\hline $3-5$ & 191 & 52.3 \\
\hline$>5$ & 13 & 3.6 \\
\hline \multicolumn{3}{|c|}{ Number of living children } \\
\hline $1-2$ & 155 & 42.5 \\
\hline $3-4$ & 183 & 50.1 \\
\hline$\geq 5$ & 27 & 7.4 \\
\hline \multicolumn{3}{|c|}{ Number of abortions } \\
\hline 0 & 286 & 78.4 \\
\hline 1 & 54 & 14.8 \\
\hline 2 & 17 & 4.7 \\
\hline$>3$ & 8 & 2.2 \\
\hline \multicolumn{3}{|c|}{ Duration between current and previous pregnancy (years } \\
\hline$\leq 2$ & 174 & 47.7 \\
\hline $3-5$ & 89 & 24.4 \\
\hline$>5$ & 102 & 27.9 \\
\hline Range & $0-20$ & \\
\hline Mean $\pm S D$ & $4.1=$ & \\
\hline \multicolumn{3}{|c|}{ Number of desired children } \\
\hline$<3$ & 264 & 72.3 \\
\hline $3-5$ & 95 & 26.0 \\
\hline$>6$ & 6 & 1.6 \\
\hline \multicolumn{3}{|c|}{ Number of desired children by husband } \\
\hline$<3$ & 204 & 55.9 \\
\hline $3-5$ & 151 & 41.4 \\
\hline$>6$ & 10 & 2.7 \\
\hline
\end{tabular}

Table 2 illustrates that (31.8\%) of the studied women had four times pregnancy and more. In addition, (52.3\% and 50.1\% respectively) had delivered from three to five times and had three to four living children. Also, more than three quarters $(78.4 \%)$ had no abortion. Moreover, $(47.7 \%)$ had interpregnancy interval of two years and less with the last pregnancy. Concerning the desired number of children, (26\%) of the studied women desired to have three to five children, while $(55.9 \%)$ of their husbands desired to have less than three children.

Table 3 showes that there was highly statistical significant association between age, family size and family income and unintended pregnancy with a value $(p \leq .001)$.Also, women from rural residence and not working women had a statistical significant with unintended pregnancy with a value ( $p=$ $.005)$. 
Table 3. Comparison of the socio-demographic characteristics among pregnant women with and without previous unintended pregnancy $(n=365)$

\begin{tabular}{|c|c|c|c|c|c|c|}
\hline & \multicolumn{2}{|c|}{$\begin{array}{c}\text { Pregnant women without } \\
\text { history of previous unintended } \\
\text { pregnancy }(\mathrm{n}=\mathbf{2 5 3})\end{array}$} & \multicolumn{2}{|c|}{$\begin{array}{l}\text { Pregnant women with history } \\
\text { of previous unintended } \\
\text { pregnancy }(n=112)\end{array}$} & \multicolumn{2}{|c|}{ Chi square test } \\
\hline & $\mathbf{N}$ & $\%$ & $\mathbf{N}$ & $\%$ & $\chi^{2}$ & $p$ \\
\hline \multicolumn{7}{|l|}{ Age } \\
\hline$\leq 25$ & 98 & 38.7 & 4 & 3.6 & & \\
\hline $26-30$ & 39 & 15.4 & 24 & 21.4 & & \\
\hline $31-35$ & 47 & 18.6 & 28 & 25.0 & & \\
\hline$>35$ & 69 & 27.3 & 56 & 50.0 & 49.244 & $<.001$ \\
\hline \multicolumn{7}{|l|}{ Age at marriage } \\
\hline$\leq 15$ & 20 & 7.9 & 15 & 13.4 & & \\
\hline $16-20$ & 174 & 68.8 & 70 & 62.5 & & \\
\hline $21-25$ & 52 & 20.6 & 27 & 24.1 & & \\
\hline$>25$ & 7 & 2.8 & 0 & 0.0 & 6.447 & .092 \\
\hline \multicolumn{7}{|l|}{ Educational level } \\
\hline Illiterate & 38 & 15.0 & 22 & 19.6 & & \\
\hline Read and write & 51 & 20.2 & 25 & 22.3 & & \\
\hline Middle education & 120 & 47.4 & 55 & 49.1 & & \\
\hline High education & 44 & 17.4 & 10 & 8.9 & 4.987 & .173 \\
\hline \multicolumn{7}{|l|}{ Residence } \\
\hline Rural & 202 & 79.8 & 101 & 90.2 & & \\
\hline Urban & 51 & 20.2 & 11 & 9.8 & 5.882 & .015 \\
\hline \multicolumn{7}{|l|}{ Occupation } \\
\hline Housewife & 212 & 83.8 & 84 & 75.0 & & \\
\hline Working & 35 & 13.8 & 28 & 25.0 & & \\
\hline Student & 6 & 2.4 & 0 & 0.0 & 9.004 & .011 \\
\hline \multicolumn{7}{|l|}{ Family size } \\
\hline $1-3$ & 96 & 37.9 & 2 & 1.8 & & \\
\hline $4-6$ & 148 & 58.5 & 79 & 70.5 & & \\
\hline$>6$ & 9 & 3.6 & 31 & 27.7 & 80.831 & $<.001$ \\
\hline \multicolumn{7}{|l|}{ Family income } \\
\hline Not enough & 131 & 51.8 & 82 & 73.2 & & \\
\hline Enough & 115 & 45.5 & 20 & 17.9 & & \\
\hline Enough and save & 7 & 2.8 & 10 & 8.9 & 28.427 & $<.001$ \\
\hline
\end{tabular}

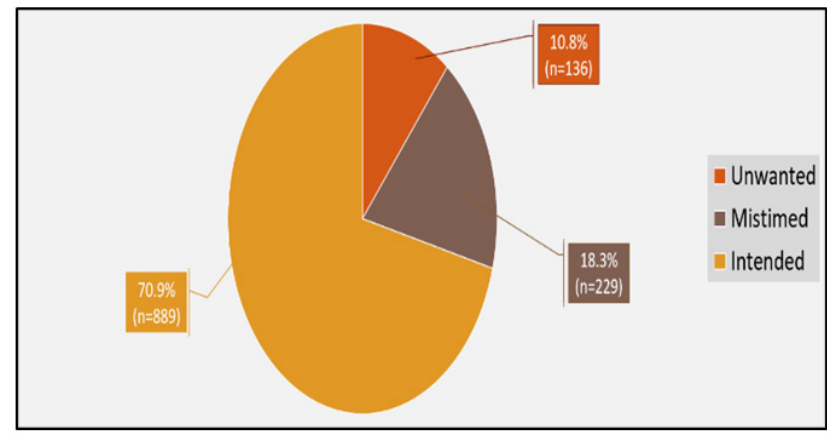

Figure 1. Pregnancy intention status among studied women

Table 4 shows that shows that women with 4 times and more gravida and Para with number of living children three and more and duration between current and previous pregnancy two years or less was highly statistical significant associated with unintended pregnancy with a value $(p \leq .001)$, while the number of abortions had a statistical significant with unintended pregnancy with a value $(p=.005)$.

Figure 1 shows the distribution of the studied women according to their intention of pregnancy. The figure shows that nearly one third of the studied women $(29.1 \%)$ were exposed to unintended pregnancy.

Figure 2 clarifies that $(34.1 \%)$ of the studied women reported that they exposed to contraceptive failure due to oral contraceptive pills usage, $(22.1 \%)$ due to intrauterine device usage, $(18.6 \%)$ due to natural methods usage and $(4.7 \%)$ due to subdermal implants.

Figure 3 reveals that $(45.8 \%)$ of the studied women reported 
that they didn't use family planning due to health problems, to poor knowledge about FP methods.

$(33.6 \%)$ due to no expectation for pregnancy and $(3.7 \%)$ due

Table 4. Comparison of the obstetric history between pregnant women with and without previous unintended pregnancy (n $=365$ )

\begin{tabular}{|c|c|c|c|c|c|c|}
\hline & \multicolumn{2}{|c|}{$\begin{array}{c}\text { Pregnant women without history } \\
\text { of previous unintended } \\
\text { pregnancy }(n=253)\end{array}$} & \multicolumn{2}{|c|}{$\begin{array}{l}\text { Pregnant women with history } \\
\text { of previous unintended } \\
\text { pregnancy }(n=112)\end{array}$} & \multicolumn{2}{|c|}{ Chi square test } \\
\hline & $\mathbf{N}$ & $\%$ & $\mathbf{N}$ & $\%$ & $\chi^{2}$ & $p$ \\
\hline \multicolumn{7}{|c|}{ Gravidity } \\
\hline 1 & 60 & 23.7 & 6 & 5.4 & & \\
\hline 2 & 73 & 28.9 & 15 & 13.4 & & \\
\hline 3 & 57 & 22.5 & 38 & 33.9 & & \\
\hline$\geq 4$ & 63 & 24.9 & 53 & 47.3 & 38.321 & $<.001$ \\
\hline \multicolumn{7}{|l|}{ Parity } \\
\hline $1-2$ & 137 & 54.2 & 24 & 21.4 & & \\
\hline $3-5$ & 116 & 45.8 & 75 & 67.0 & & \\
\hline$\geq 6$ & 0 & 0.0 & 13 & 11.6 & 54.825 & $<.001$ \\
\hline \multicolumn{7}{|c|}{ Number of living children } \\
\hline $1-2$ & 137 & 54.2 & 18 & 16.1 & & \\
\hline $3-4$ & 109 & 43.1 & 74 & 66.1 & & \\
\hline$\geq 5$ & 7 & 2.8 & 20 & 17.9 & 58.589 & $<.001$ \\
\hline \multicolumn{7}{|c|}{ Number of abortions } \\
\hline 0 & 202 & 79.8 & 84 & 75.0 & & \\
\hline 1 & 37 & 14.6 & 17 & 15.2 & & \\
\hline 2 & 6 & 2.4 & 11 & 9.8 & & \\
\hline$\geq 3$ & 8 & 3.2 & 0 & 0.0 & 13.041 & .005 \\
\hline \multicolumn{7}{|c|}{ Duration between current and previous pregnancy } \\
\hline$\leq 2$ & 141 & 55.7 & 33 & 29.5 & & \\
\hline $3-5$ & 56 & 22.1 & 33 & 29.5 & & \\
\hline$\geq 6$ & 56 & 22.1 & 46 & 41.1 & 22.909 & $<.001$ \\
\hline \multicolumn{7}{|c|}{ Number of children desired } \\
\hline$<3$ & 176 & 69.6 & 88 & 78.6 & & \\
\hline $3-5$ & 73 & 28.9 & 22 & 19.6 & & \\
\hline$\geq 6$ & 4 & 1.6 & 2 & 1.8 & 3.421 & .181 \\
\hline \multicolumn{7}{|c|}{ Number of children desired of husband } \\
\hline$<3$ & 144 & 56.9 & 60 & 53.6 & & \\
\hline $3-5$ & 101 & 39.9 & 50 & 44.6 & & \\
\hline$\geq 6$ & 8 & 3.2 & 2 & 1.8 & 1.111 & .574 \\
\hline
\end{tabular}

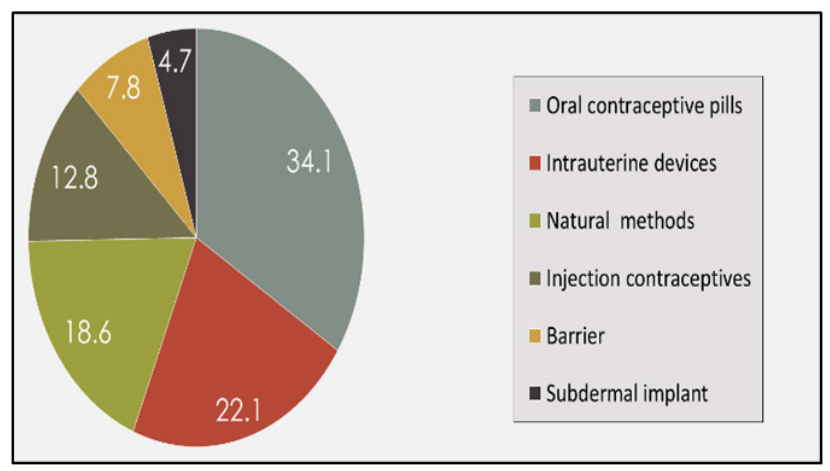

Figure 2. Contraceptive failure among studied women during current unintended pregnancy $(n=258)$

\section{Discussion}

The present study was implemented to assess the prevalence and associated factors of unintended pregnancy among pregnant women attending antenatal clinics. The findings of the present study answered the research question concerning the prevalence of UP. The present study finding showed that nearly one third $(29.1 \%)$ of the studied women were exposed to unintended pregnancy.

This finding was in the same line with descriptive study done by Kassahun. ${ }^{[13]}$ Who found that $(29.7 \%)$ of the study sample were exposed to unintended pregnancy. Additionally, another study conducted by Aly. ${ }^{[14]}$ Who revealed that nearly one third $(31 \%)$ were exposed to UP? The present 
study finding is higher than the rates announced by previous studies in Egypt. The Egyptian Demographic Health Survey (EDHS) 2014 reported that the prevalence of UP was (16\%).

However, the finding of the current study is lower than the study which done in USA and revealed that the prevalence of UP was $45 \% .{ }^{[15]}$ Ghana $40 \% .{ }^{[16]}$ South Africa 64\%. ${ }^{[17]}$ Arsi Negele, Ethiopia 41.5\%. ${ }^{[18]}$ The differences among the various studies addressing the above-mentioned prevalence and the present one has been attributed to socio cultural and demographic differences, study design differences, use of FP methods, high prevalence of adolescent pregnancy and pregnancy in unmarried girls which is scarce in Egypt.

Concerning the types of UP, the present finding revealed that $229(18.3 \%)$ of the studied women were exposed to mistimed pregnancy, while $136(10.8 \%)$ were exposed to unwanted pregnancy. This finding was in agreement with Mohamed, ${ }^{[19]}$ who revealed that $(17.7 \%)$ were mistimed and $(13.0 \%)$ were unwanted pregnancy.

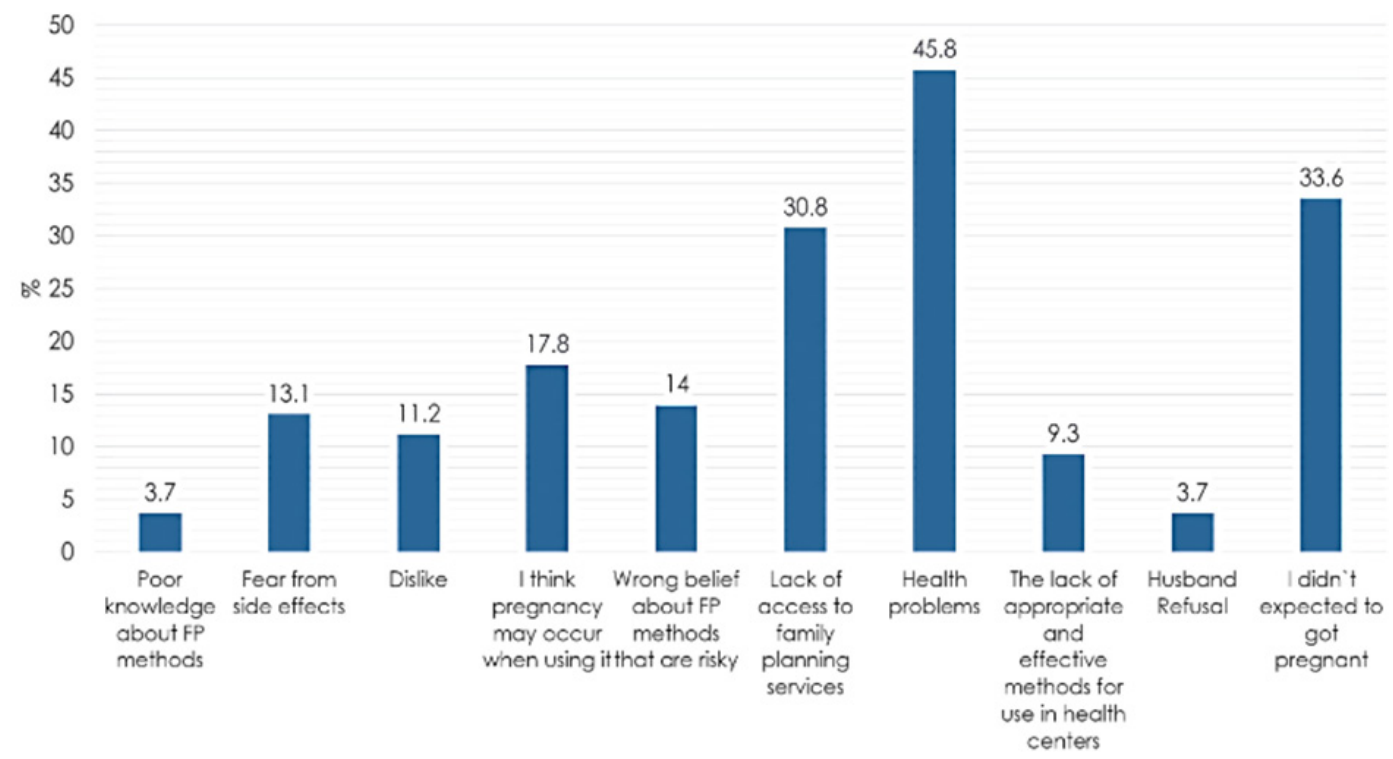

Figure 3. Shows distribution of the reasons for not using family planning methods among study women $(\mathrm{n}=107)$

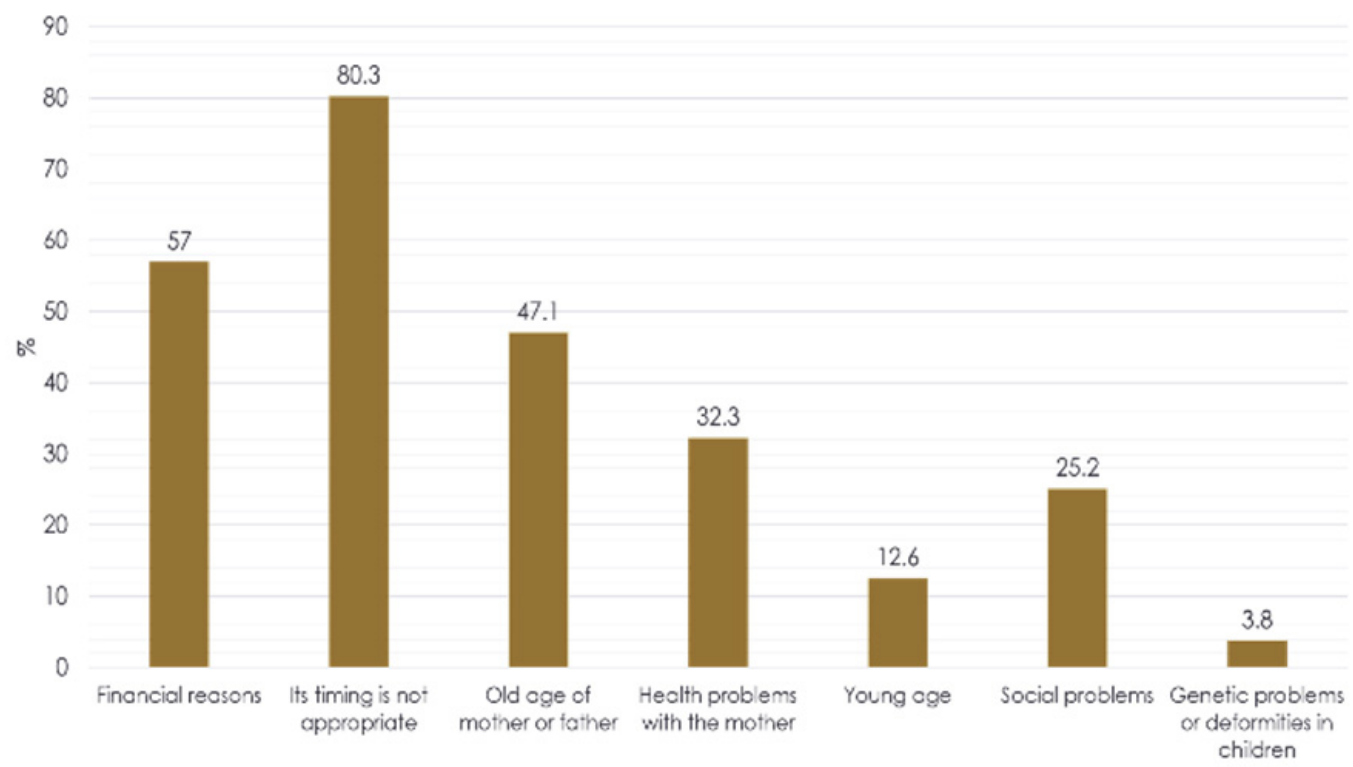

Figure 4. Distribution of the reasons that made this pregnancy unintended $(n=365)$ 
The present study finding showed that age, family size and family income, residence, occupation, age at first marriage, gravidity, parity, number of living children, number of children desired, number of abortions and duration between current and previous pregnancy are important factors which significantly associated with the occurrence of UP.

The present study revealed that UP is significantly associated with the extremes of childbearing age (less than 20 years of age and 35 years of age and above). This may be due to women aged 35 years and above were inappropriately use family planning methods (FP).

This finding was in the same line with Andini, ${ }^{[20]}$ who revealed that women less than 20 years and more than 35 years were more likely to experience UP than women aging 20-35 years. In congruent to this finding was the study of AlmasiHashiani ${ }^{[21]}$ who reported that the prevalence of UP was high in older age groups.

The present study showed that women with UP were married at the age of 20 years or less. This may be due to women who married before 18 years were more likely to be less educated, socially disadvantage and less autonomous in making reproductive decisions. Thus, they were more likely to take the decision of pregnancy by their husbands, families and culture. Similarly, Gite ${ }^{[22]}$ in Ethiopia, Belay. ${ }^{[23]}$ In North West Ethiopia and Aly Nor [14]., Amasha, Salah Salama [24] in Port-said, Egypt found that the age at the first marriage less than or equal to 18 years were six times more likely to experience UP than their counter parts. Unlikely, AbdelHaleem ${ }^{[25]}$ revealed that women with unintended pregnancy were married at the age more than 20 compared to those who had intended pregnancy.

Concerning residence and occupation, the current study found that the majority of women were lived in rural areas and were housewives. This association may be due to illiteracy, poverty, higher fertility rate, limited availability of health services, and poor utilization of social and health services that characterize rural areas. This finding was matched with Goshu ${ }^{[26]}$ who found that the majority of the studied women were lived in rural areas and unemployed. On the other hand, Mohamed ${ }^{[19]}$ showed that employed women were more likely had UP than unemployed women.

Regarding family size and income, the present study finding showed that there was significant association between family size and income with UP as the women with family size more than 4 members and socially disadvantaged were more likely to have UP. This may be due to families with increased number of children already reached the desired number of children. Also, women who financially disadvantaged were inappropriately use FP methods as a result of its cost.

This is supported by Beyene ${ }^{[15]}$ who stated that the risk of UP increased with increasing family size. In addition, Bekele ${ }^{[17]}$ and Haffejee ${ }^{[12]}$ reported that socially disadvantaged women with family size more than 5 members were 8 times more likely to have UP. These findings were in contrast with recent researches carried out by Ayele, ${ }^{[?]}$ who stated that there was no significant association between socioeconomic status of women and unintended pregnancy.

The present study found that nearly one third of women with UP were multigravida. This finding was almost similar to $\mathrm{Goshu}^{[26]}$ who found that when gravidity increased, the probability of exposure to UP was increased. Moreover, Fite ${ }^{[18]}$ revealed that women whose gravidity 5 and above were 3.88 times more likely to have unintended pregnancy than those whose gravidity 1-2.

Furthermore, another finding revealed that more than half of pregnant women had three and more parities. This finding was in agreement with Bekele, ${ }^{[17]}$ who found that increased parity more than were more likely to have unintended pregnancy.

Concerning the number of living children, the present study reported that half of the studied sample had three to four living children. This is supported by Mohamed, ${ }^{[19]}$ who found that living children 5 and above was a risk factor for unwanted pregnancy.

Regarding the desired number of children, the finding of the present study showed that half of the studied women and their husbands desired to have less than three children. This finding in agreement with Beyene ${ }^{[15]}$ who noticed that women desired to have less than four children were 2.89 times more likely to report UP compared to women desired to have six or more number of children. The present study revealed that nearly half of the studied sample had inter-pregnancy interval of two years and less with the last pregnancy. Similarly, Fite $^{[18]}$ found that short birth spacing of less than 2 years were also found to be significantly associated with mistimed pregnancies.

The present study finding revealed that contraceptive failure $(70.7 \%)$ was the major reason for UP. While, nearly one third had UP due to not using or discontinued FP method before pregnancy. Several studies in agreement with the current study finding who found that contraceptive failure was the major reason for UP followed by not using FP for mistimed pregnancy. ${ }^{[17]}$

The present finding revealed that contraceptive failure was the main reason for UP. Most of the failure rate was due to 
using pill either combined or progesterone only, followed by intrauterine devices, natural methods, injectable, chemical and barrier methods. The least ranked were subdermal methods. This is partially in agreement with Mohamed, ${ }^{[19]}$ who reported that the failure rate is due to pill usage, followed by natural methods, chemical and barrier methods. The least ranked were injectable methods.

\section{Conclusions}

The study questions were answered; the prevalence of unintended pregnancy among pregnant women attending antenatal clinics was high $(29.1 \%)$ which represented a public health problem in Mansoura city. Additionally, regarding the answer of the second question, it is concluded that increased gravidity, parity, contraception failure, the extremes of age, housewives women, and those living in rural areas with low family income and big family size were the most associated factors for unintended pregnancy.Furthermore, contraceptive failures were the main reasons for unintended pregnancy in the present study. The highlighted failure rate was among oral contraceptives usage.

\section{RECOMMENDATION}

(1) Antenatal and postnatal counseling programs for women using simple illustrative booklets and pamphlets in Arabic language can be used to reduce the unmet need for contraception.

(2) Increasing awareness of the women about factors associated with the occurrence of unintended pregnancy and the consequences of UP on women and their families.

(3) Developing campaigns especially to rural areas which include a series of information and education activities directed to women of all ages describing available contraceptive methods.

\section{ACKNOWLEDgeMENTS}

The researchers would like to thank all participants for their cooperation during the study.

\section{CONFlicts of InTEREST Disclosure}

The authors declare they have no conflicts of interest.

\section{REFERENCES}

[1] Wagan F, Siyal AA, Ali R, et al. Major Consequences, Determinants and Obstetrical Outcomes of Unintended Pregnancy. National Editorial Advisory Board. 2018; 29(11): 43.

[2] Bellizzi S, Pichierri G, Menchini L, et al. The impact of underuse of modern methods of contraception among adolescents with unintended pregnancies in 12 low-and middle-income countries. Journal of Global Health. 2019; 9(2). PMid: 31673342. https: //doi.org/10.7189/jogh.09.020429

[3] WHO. 2018 High rate of unintended pregnancy. Updated October 2019 [cited 2 February 2020]. Available from: https://www . who.int/news-room/detail/25-10-201 9-high-rates-of-unintended-pregnancies-linked-to-g aps-in-family-planningstudy-services-new-who-

[4] Ministry of Health and Population [Egypt], El-Zanaty and Associates [Egypt], and ICF International. Egypt demographic and health survey 2014. Cairo, Egypt and Rockville, Maryland, USA. 2015.

[5] Hall KS, Dalton VK, Zochowski M, et al. Stressful life events around the time of unplanned pregnancy and women's health: exploratory findings from a national sample. Maternal and Child Health Journal. 2017; 21(6): 1336-1348. PMid: 28120290. https: //doi.org/10.1007/s10995-016-2238-z

[6] Alemu A, Abageda M, Assefa B, et al. Low birth weight: prevalence and associated factors among newborns at hospitals in KambataTembaro zone, Southern Ethiopia 2018. The Pan African Medical Journal. 2019; 34. PMid: 31819784. https://doi.org/10.116 04/pamj . 2019.34.68.18234

[7] Omani-Samani R, Ranjbaran M, Mohammadi M, et al. Impact of unintended pregnancy on maternal and neonatal outcomes. The Journal of Obstetrics and Gynecology of India. 2019; 69(2): 136-141. PMid: 30956467. https://doi.org/10.1007/s13224-018-1125-5

Published by Sciedu Press
[8] Galli A, Leuenberger A, Dietler D, et al. Tropical Medicine andpi8uiiko International Health and the 2030 Agenda for Sustainable Development. Tropical Medicine \& International Health. 2020; 25(1): e1-e13. PMid: 31983079. https://doi .org/10.1111/tm i. 13368

[9] People H. Framework: The vision, mission, and goals of Healthy People 2020. US Department of Health.2020.

[10] Habib MA, Raynes-Greenow C, Nausheen S, et al. Prevalence and determinants of unintended pregnancies amongst women attending antenatal clinics in Pakistan. BMC Pregnancy and Childbirth. 2017; 17(1): 156. PMid: 28558671. https://doi.org/10.1186/s128 84-017-1339-z

[11] Barrett G, Wellings K. What is a 'planned'pregnancy? Empirical data from a British study. Social Science \& Medicine. 2020; 55(4): 545557. https://doi.org/10.1016/S0277-9536(01) 00187-3

[12] Haffejee F, O'Connor L, Govender N, et al. Factors associated with unintended pregnancy among women attending a public health facility in KwaZulu-Natal, South Africa. South African Family Practice. 2018; 60(3): 1-5.https://doi.org/10.4102/safp.v60i3.488 4

[13] Kassahun EA, Zeleke LB, Dessie AA, et al. Factors associated with unintended pregnancy among women attending antenatal care in Maichew Town, Northern Ethiopia, 2017. BMC Research Notes. 2019; 12(1): 381. PMid: 31277714. https://doi.org/10.1186/ s13104-019-4419-5

[14] Aly Nor S, Amasha AR, Salah Salama N, et al. Prevalence and Associated Factors of Unintended pregnancy in Port-said. Port Said Scientific Journal of Nursing. 2019; 6(1): 101-120. https: //doi.org/10.21608/pssjn.2019.34039

[15] Beyene GA. Prevalence of unintended pregnancy and associated factors among pregnant mothers in Jimma town, southwest Ethiopia: a cross sectional study. Contraception and Reproductive Medicine. 
2019; 4(1): 8. PMid: 31321072. https ://doi.org/10.1186/s4 0834-019-0090-4

[16] Nyarko SH. Unintended pregnancy among pregnant women in Ghana: prevalence and predictors. Journal of Pregnancy. 2019. PMid: 30834145. https://doi.org/10.1155/2019/2920491

[17] Bekele YA, Fekadu GA. Factors associated with unintended pregnancy in Ethiopia; further analysis of the 2016 Ethiopian demographic health survey data. 2019. https://doi.org/10.21203/r s. $2.14900 / v 2$

[18] Fite RO, Mohammedamin A, Abebe TW. Unintended pregnancy and associated factors among pregnant women in Arsi Negele Woreda, West Arsi Zone, Ethiopia. BMC Research Notes. 2018; 11(1): 671. PMid: 30223872. https://doi.org/10.1186/s13104-018-3 778-7

[19] Mohamed EAEB, Hamed AF, Yousef FM, et al. Prevalence, determinants, and outcomes of unintended pregnancy in Sohag district, Egypt. Journal of the Egyptian Public Health Association. 2019; 94(1): 1. PMid: 32813191. https://doi.org/10.1186/s42506 -019-0014-9

[20] Andini MA, Mutahar R. Trends and Determinants of Unintended Pregnancy Occurrence among Married Women Aged 15-49 Years in Indonesia. In 4th International Symposium on Health Research (ISHR 2019) (pp. 361-367). Atlantis Press; 2020. https : //doi.or g/10.2991/ahsr.k.200215.069

[21] Almasi-Hashiani A, Omani-Samani R, Sepidarkish M, et al. Unintended Pregnancy in Iran: Prevalence and Risk Factors. International
Journal of Women's Health and Reproduction Sciences. 2019; 7(3): 319-323. https://doi.org/10.15296/ijwhr.2019.53

[22] Gite A, Liulseged N, Seyife H, et al. Unintended pregnancy: magnitude and associated factors among pregnant women in Arba Minch Town, Gamo Gofa Zone, Ethiopia, 2015. Reprod Syst Sex Disord 2016; 5(193): 1-6. https ://doi.org/10.4172/2161-038X.10 00193

[23] Belay D, Alem A, Zerihun S, et al. Unintended pregnancy and associated factors among unmarried female students: A case of Bahir Dar University. Heliyon. 2020; 6(6): e04309. PMid: 32637699. https://doi.org/10.1016/j.heliyon.2020.e04309

[24] Abdel-Haleem SAR, Amasha HAR, Salama NS. Unintended Pregnancy and Family Planning Counseling Guideline on Maternity Nurse Performance: Clinical Based Study. The Malaysian Journal of Nursing. 2019; 10(3): 99-11. https://doi.org/10.31674/mjn. 201 9.v10i03.014

[25] Goshu YA, Yitayew AE. Prevalence and determinant factors of unintended pregnancy among pregnant women attending antenatal clinics of Addis Zemen hospital. PloS One. 2019; 14(1): e0210206. PMid: 30699140. https://doi.org/10.1371/journal.pone .0210206

[26] Bekele H, Dheressa M, Mengistie B, et al. Unintended Pregnancy and Associated Factors among Pregnant Women Attending Antenatal Care at Bako Tibe District Public Health Facility, Oromia Region, Ethiopia. Journal of Pregnancy. 2020. PMid: 32257441. https://doi.org/10.1155/2020/3179193 